Portland State University

PDXScholar

$5-24-2018$

\title{
Community Music for Human Development : a Brain- Centered Approach to Outreach
}

Jesse M. Hamlin

Portland State University

Follow this and additional works at: https://pdxscholar.library.pdx.edu/honorstheses

Let us know how access to this document benefits you.

\section{Recommended Citation}

Hamlin, Jesse M., "Community Music for Human Development : a Brain-Centered Approach to Outreach" (2018). University Honors Theses. Paper 531.

https://doi.org/10.15760/honors.536

This Thesis is brought to you for free and open access. It has been accepted for inclusion in University Honors Theses by an authorized administrator of PDXScholar. Please contact us if we can make this document more accessible: pdxscholar@pdx.edu. 
Community Music for Human Development : A Brain-Centered Approach to Outreach

Jesse Hamlin

Adviser

Dr. Bill Griesar

Portland State University

Honors Thesis 


\begin{abstract}
In an effort to combat the harmful physiological, societal, and psychological effects of the cutting of arts and music program budgets in public schools, and close the achievement gap for those in lower socioeconomic classes and underrepresented populations, this thesis created a functional community music training program, especially for homeless youth in Portland, OR. The author reviewed current literature across disciplines to form a curriculum based on evidence in psychological, educational, and cognitive neuroscience research. The curriculum was collaboratively formed with active music training professionals. The intervention was piloted via the ongoing collaboration between Portland-based arts-integrated science outreach group NW Noggin, and the daytime homeless youth center, p:ear. Observed efficacy, reaction, and implications for future efforts are discussed.
\end{abstract}

Keywords: Homelessness, Arts-Integration, Music, Education, Neuroscience. 


\section{Literature Review}

\section{Arts Programs and Educational Policy}

In the last year, our government has proposed the dissolution of nineteen publicly funded arts programs, including the national endowment for the arts. (Chu, 2017). According to the Nation's Report Card (NAEP, 2016), art and music scores are already on the decline since 2008 and attendance in art and music programs has dropped as well. This problem is not a new one. In 2001, following passage of the "No Child Left Behind Act," there was immediately an approximately $22 \%$ decrease in instructional time given to art and music in public schools nationwide (Whitehorne 2006). Although the No Child Left Behind Act does contain art as one of its "core principles," the progress measures used (e.g. standardized testing for math, reading), force schools to direct their curriculum towards helping the students pass these tests. Now more than ever, students need affordable extra-curricular programs to stimulate the creativity, achievement, esteem, and neuroplasticity that only the arts can deliver.

\section{Brain-Based Education}

Educational research has recently combined forces with the field of neuroscience to look at some of the more physiological bases for learning and development.

Brain-based educational research looks at brain health and the learning environment in combination with content learning. This is a more holistic approach because it takes into account sleep, nutrition, trauma, and racial/ethnic/socioeconomic diversity as well as pedagogy. This approach is also founded in more quantifiable terms, which means that 
the research is less subjective and more applicable in working towards educational policy change.

For example, it is intuitive that arts integration in classrooms engages students through novelty and forces them to think about information in new ways. But in viewing this theory through the lens of cognitive neuroscience, it has been shown that thinking about information in a variety of ways improves retention through the cognitive neuroscience of semantics, cues, enactment, oral production, emotional arousal, and pictorial representation (Rinne, et al., 2011). Cognitive neuroscience research has also found evidence that long-term artistic training can "macroscopically imprint a neural network system of spontaneous activity..." Simply put, artistic training nurtures the growth of more flexible and resilient neurons in the brain (Limb, et al., 2014). With this perspective, new doors are opened to educational research and practice, and more robust and substantial methods of teaching and learning can be established.

\section{Music on the Developing Brain}

More specifically, music-making, especially improvisation, has been shown to create a dissociation between the medial prefrontal cortex and the lateral prefrontal cortex that stimulates creative generation while interrupting inhibition (Lopez-Gonzales \& Limb, 2012). This means that during the process of creation, inhibitions are lowered, helping students learn without the fear of being wrong. In addition, heightened brain activity, in many more parts of the brain, helps create a stronger network by which to draw on, and increases long term memory of the content (Rinne, et al., 2011). There is also a theory that learning to play a musical instrument in childhood will stimulate 
cognitive development and enhance skills in extramusical areas, which is commonly referred to as transfer (Bangerter \& Heath, 2004). Though this theory is controversial to some, there is evidence to show that in only 15 months of instrumental music training on the developing brain, there are significant, visible, physiological changes that happen in the brain (Hyde et al., 2009), many of which can still be seen, and are beneficial, more than 40 years after stopping musical training (White-Schwoch, Carr, Anderson, Strait, \& Kraus, 2013).

Behaviorally speaking there is evidence that musical aptitude is associated with literacy (Anvari, Trainor, Woodside, \& Levy, 2002; Lamb \& Gregory, 1993), general intelligence (Lynn, Wilson, \& Gault, 1989), verbal memory (Ho, Cheung, \& Chan, 2003), spatial ability (Hetland, 2000), reading ability (Hurwitz, Wolff, Bortnick, \& Kokas, 1975), selective attention (Hurwitz et al., 1975), and mathematics achievement (Cheek \& Smith, 1999). One study even found that in just 36 weeks of musical training, there were more significant increases in the IQ of 6 year olds than in those without musical training (Schellenberg, 2004). Because music encourages plasticity in the brain, it has been shown that regular, casual engagement with music-making prevents the neurological decline that comes with aging and lowers overall "brain-age" (Rogenmoser et al., 2017). In a very interesting study by Kraus, Slater, Thompson, Hornickel, Strait, Nicol, \& White-Schwoch (2014), the authors addressed the problem of high levels of ambient noise, and fewer opportunities for complex language interaction, in children who come from disadvantaged backgrounds by providing community music lessons. They found that these community music lessons helped spark the neuroplasticity that many of the 
children from disadvantaged backgrounds would typically miss out on (Kraus et al., 2017). Another study found that children who actively engaged in instrument training had faster and more robust neural processing of speech sound as well as higher scores in literacy. The authors conclude that music-making promotes experience-dependent neuroplasticity and auditory learning (Kraus et al., 2014). These findings were not particularly new. In a much older study that looked at the relationship between music training and reading skills such as phonemic discrimination, reading performance, and correct changes of pitch and timbre, it was found that discrimination of musical sounds gained from musical training is related to reading performance, literacy, and linguistic achievement (Lamb \& Gregory, 1993).

Arts Integration in the Classroom

The benefits of arts integration in classrooms is not a new topic of research. There is evidence in many fields that the arts have positive effects on people on many levels. For example, there is longitudinal evidence to show that arts-integrated educational systems result in higher long-term retention of subject matter taught (Hardiman, Rinne, \& Yarmolinskaya, 2014). Even more interesting is that this increase in retention was found to be even larger in populations of students with lower levels of reading achievement (Hardiman et al., 2014). Findings like these are not uncommon, in a study conducted by UCLA on the effects of the arts on human development, it was found that academic achievement was positively correlated with arts involvement and the gains became more pronounced over time. Furthermore, the gains in academic achievement were even more pronounced in those students from the lowest 
socioeconomic demographics, and those of the lowest academic achievement, or considered "at risk" (Catterall, Chapleau, \& Iwanaga, 1999). These findings give us some preliminary evidence towards closing achievement gaps, and creating more universally applicable curriculum.

In a research review on the pros and cons of arts-integration in the classroom, evidence was found to support that arts-integrated classrooms had increased student involvement, enhanced higher order thinking, more entry points for content discussion and discovery, higher cultural literacy and applicability, enhanced imagination and visualization, more engagement in intra/interpersonal skills, more collaborative work, improved spatial thinking abilities in math settings, higher rates of healthy risk-taking and creative problem solving, and more welcoming classroom environment towards diversity and multiculturalism (Gullat, 2008).

There are several operations that have been thought to be reasons for the effectiveness of arts-integration. Arts-based learning requires complex and effective operations such as repetition, formalization, dynamic variation, exaggeration, and surprise, which demand more of student's attention, engagement, sensory perception and reaction, and even physical movement (Hartle, 2015). It has also been found arts-integration in the classroom, even as a supplement to lessons in other subjects, helps students create meaning with the content and listen more attentively, increasing knowledge gained and even performance on tests (Gullat, 2008). One of the biggest advantages to arts-integrated learning environments is that they are altogether more "fun." In a qualitative study conducted by the Demoss \& Morris (2002), similar amounts 
of correlation were found between arts-integration and academic achievement, and arts-integration and "fun" or enjoyment with the subject matter. When students enjoy the lesson, which they are more likely to do if there is an arts element involved, they make deeper and more profound connections with it (Demoss \& Morris, 2002). They are also more apt to create meaning from the subject matter, which will increase student engagement with the subject, their teachers, and their peers. It will also promote retention of the subject matter, and cultivate higher levels of motivation to learn and comprehend the subject matter in students (Lynch, 2007).

Beyond academic achievement based measures of the benefits of arts-integration in classrooms, there are long-term benefits to the entire teaching/learning infrastructure. A research review on differences between school settings with arts-integration and those without found that "Gains in arts-integrated schools went well beyond the basics and test scores." Arts integration gave teachers and faculty the energy that led to broader school changes. For example, teachers shifted schedules in order to accommodate the pursuing of questions in depth. Parents became more involved in student projects as well as the school in order to see their children's work in performances or exhibitions. Teachers took on different types of leadership roles, motivating themselves by motivating their students. Art and music faculty became critical resources for classroom teachers and collaboration across disciplines became normal. As teachers inquired into how arts integration works, they were engaged in new forms of professional development. Creative assessment 
strategies became more important than standardized tests and became more focused on student work and development (Rabkin \& Redmond, 2006).

Overall, educational research, similar to cognitive neuroscientific research, offers a strong foundation for the utility and advantages of arts-integrated education. Of particular interest is the tendency within the literature to show the effects of arts-integration on the achievement gap, specifically on the advantageous effects for "at-risk" students from lower socioeconomic backgrounds. Not only does it have the highest effect size for academic achievement in this demographic, it has been shown to compensate for differences in brain development and neuroplasticity within this group. This thesis aims to accommodate these benefits in an extracurricular setting, and help make up for the consequences many children, faculty, and school environments face when arts-integration is not encouraged, or is altogether non-existent.

Homelessness and the Brain

The homeless are not only consistently faced with sleep deprivation, high levels of ambient noise, and a lack of opportunities to engage in complex language interactions or art-making. They also face extreme dehumanization. Neuroimaging shows that recognition of people in extreme out-groups (homeless, addicts, etc.) is actually processed in the brain differently than people of in-groups. The human brain tends to process them more similarly to an "object of disgust" than an actual person (Harris \& Fisk, 2006).

This level of dehumanization and social isolation, in combination with the variability of brains and brain networks involved in social and rational decision making 
during adolescence (Casey, Jones, \& Hare, 2008), creates an environment that can be hostile to brain development. Impairments have been found in visuomotor skills, problems solving skills, judgment, logical thinking, and processing speed. In addition, homeless children generally score lower on tests of verbal abilities, and have significant deficits in attention (Edidin, et al., 2012). Considering the high rates of mental illness, sleep deprivation, and inequities in access to resources (Smedley et al, 2001) within homeless communities, the need for intervention seems obvious.

The current system of public education values standardized curricula, testing, and attendance, rather than creativity, diversity, and innovation. Because of this, many of the youth who would have the most benefit from arts-integrated teaching practices become unmotivated and unenthused, falling behind in school, and are at higher risk for homelessness.

Overall, there is strong evidence that music has much to offer in terms of brain development, neuroplasticity, and intellectual achievement. Access to the arts, especially music can help develop otherwise unstimulated brain regions that homeless youth have fewer opportunities to stimulate. The arts also provide a platform for artists to express themselves, find an audience, and be seen by people as more than their circumstances. We have formulated a curriculum informed by neuroscientific, sociological, psychological, and educational existing research that helps create holistic learning environments for homeless adolescents, who have fewer opportunities to reap the cognitive and developmental benefits of music-making. As well, we have provided a free community resource for homeless adolescents with developing brains and identities 
to learn about music theory, appreciation, instrument-training, and music-making, and help close the achievement gap between socioeconomic classes. Lastly, we have organized an event to help homeless youth see and be seen by others as artists, musicians, students, and people to help diminish the effects of dehumanization and invisibility.

\section{Curriculum}

In constructing a curriculum specifically for brain development, and mitigating the harmful effects of homelessness, we decided to focus on a few main principles that each part of the curriculum would have. Because of the limited scope of this project and the limited resources that were available to make the project happen, we chose to make this a one-day curriculum focusing on a variety of workshops that together are able to attract a broad demographic of people with various interests.

As the event was only one day the first principle we chose to focus on was inspiration. The nonprofit that I am using as a platform to launch the program, NW Noggin, is primarily an outreach organization that specializes in inspiring youth towards STEAM careers, sometimes with less than an hour of interaction with very large groups of children. Working with the outreach coordinators at NW Noggin, one of the things we found that helped children transition from interested to inspired was making sure there was some form of empowering accomplishment. In order to provide such accomplishment we designed several of the workshops to provide opportunities for the 
participant to create or accomplish something, and feel a level of empowerment or mastery over a specific musical principle or technique.

Another harmful byproduct of growing up homeless is dehumanization and invisibility. In order to mitigate the harmful effects of being chronically dehumanized and ignored, we decided to focus our workshops to include elements of collaboration and performance. Through performance, the participants will be seen and heard, looked at in the face and eyes, be complemented, and have their name learned by others, which are all humanizing experiences that many homeless have fewer opportunities for. By collaborating with others, the participants will be a part of a soundscape that would be different without them, and will have to engage in complex forms of communication, improvisation, and call and response techniques that we expect will give participants a sense of community, belonging, importance, and flow.

The last thing we chose to build the curriculum around is future orientation. Homeless youth have higher rates of depressive symptoms than non homeless youth (Ayerst, 1999). In order to help participants feel a sense of ambition, curiosity, and motivation to continue learning and mastering different musical techniques we decided to develop some workshops that give a glimpse into the potential for continuing to learn and practice theory and technique that will not be mastered within one day. We hope to help participants set musical goals, as regular musical practice and stimulation will be required to significantly improve brain development and realize the long-term effects of music on the brain. We also connected the youth to proper resources so that they can 
have opportunities to continue learning and practicing. (For Curriculum see Appendix I: Curriculum)

\section{Event Report}

On May 22nd, 2018 we were able to pilot the curriculum with it's targeted audience for about three hours. Working with volunteers from a local-to-portland art and neuroscience nonprofit called NWNOGGIN, as well as a nonprofit daytime houseless youth shelter and resource center called P:ear, we were able to teach community music to a group of houseless kids. In the class, we set up various workshops for the students to grasp basic musical ideas and techniques, and to inspire them to pursue music further. Some of the workshops present at the event included: Intro to modular synthesis, intro to signal chain processing, intro to latin rhythm/melody, basic guitar techniques, basic instrument building from recycled materials, and more.

There were various techniques that proved effective as forms for music education outreach. The first thing that got the students interested in the workshops were the unique noises coming from our side of the event space, a bit of surprise was helpful to spike interest initially. After initial interest was piqued, the music instructors showed the students their mastery of the discipline, which inspired confidence in the students towards the instructors, and made the students desire to achieve similar mastery. Next, the instructors handed off instruments and let the student's do as they would, but after a short time started teaching basic techniques to the students. This was helpful because the students were able to creatively explore the instrument but were 
given some tools to give them a sense of mastery, before losing interest. Letting the instructors craft their workshops, and shaping their teaching objectives rather than their subject and methods was helpful, especially in a volunteer setting, because the instructor's were able to teach confidently, and expertly, whilst still achieving the desired outcome of outreach towards musical training.

The students' response was overall positive. Altogether there were about 20 houseless youth that participated. Many of the students inquired about further musical and instrumental training related to the disciplines of their favorite workshops. They administrators and volunteers of the shelter reported that several students inquired about the purchase of instruments and instrument building kits after having their interest piqued by the workshops and the shelter is already in the process of accommodating those requests. As well, many of the instructor's signed up for volunteer trainings through P:ear in order to continue volunteering there and eventually be able to do more advanced one-on-one lessons with the student's that are interested.

In conclusion, the curriculum was effective in an outreach capacity, for connecting houseless youth to musical instruction, inspiring them towards instrumental training, and introducing them to new musical ideas. Unfortunately it is beyond the scope of this thesis to explore longitudinal cognitive and psychological effects of this curriculum. The hope is that the effects over time would be consistent with research in the field, and hope that more research is done in the future in order to create a clearer picture of the effects of this program and similar programs. 


\section{Works Cited}

\section{Engagement, Interest, and Emotion}

Ainley, M. (2007). Being and feeling interested: Transient state, mood, and disposition. In P. Schutz \& R. Pekrun (Eds.), Emotions and education. 147-163

Ainley, M. (2010). Interest in the dynamics of task behavior: Processes that link person and task in effective learning. In T. Urdan \& S. A. Karabenick (Eds.), Advances in motivation and achievement. The decade ahead: Theoretical perspectives on motivation and achievement 16(A), 235-264.

Ainley, M., \& Ainley, J. (2011b). Student engagement with science in early adolescence: The contribution of enjoyment to students' continuing interest in learning about science. Contemporary Educational Psychology, 36(1), 4-12.

Ainley, M., Corrigan, M., \& Richardson, N. (2005). Students, tasks and emotions: Identifying the contribution of emotions to students' reading of popular culture and popular science texts. Learning and Instruction, 15(5), 433-447.

Bergin, D. A. (1999). Influences on classroom interest. Educational psychologist, 34(2), 87-98.

Buckley, S., Hasen, G., \& Ainley, M. (2004). Affective engagement: A person-centred approach to understanding the structure of subjective learning experiences. Paper presented at the Australian Association for Research in Education (AARE).

Christenson, S. L., Reschly, A. L., \& Wylie, C. (2012). Handbook of research on student engagement. Retrieved from https://ebookcentral-proquest-com.proxy.lib.pdx.edu

Corno, L., \& Mandinach, E. B. (1983). The role of cognitive engagement in classroom learning and motivation. Educational psychologist, 18(2), 88-108. 
Fredricks, J. A., Blumenfeld, P. C., \& Paris, A. H. (2004). Student engagement: Potential of the concept, state of the evidence. Review of Educational Research, 74(1), 59-109.

Hidi, S., \& Harackiewicz, J. M. (2000). Motivating the academically unmotivated: A critical issue for the 21st century. Review of Educational Research, 70(2), 151-179.

Hidi, S., \& Renninger, K. A. (2006). The four-phase model of interest development. Educational Psychologist, 41(2), 111-127.

Pekrun, R., Goetz, T., Titz, W., \& Perry, R. P. (2002). Academic emotions in students' self-regulated learning and achievement: A program of qualitative and quantitative research. Educational Psychologist, 37(2), 91-105.

Renninger, K. A., \& Bachrach, J. E. (2015). Studying triggers for interest and engagement using observational methods. Educational Psychologist, 50(1), 58-69.

Rotgans, J. I., \& Schmidt, H. G. (2011). Situational interest and academic achievement in the active-learning classroom. Learning and Instruction, 21(1), 58-67.

Skinner, E., Furrer, C., Marchand, G., \& Kindermann, T. (2008). Engagement and disaffection in the classroom: Part of a larger motivational dynamic? Journal of Educational Psychology, 100(4), 765-781.

Fredricks, J. A., Blumenfeld, P. C., \& Paris, A. H. (2004). Student engagement: Potential of the concept, state of the evidence. Review of Educational Research, 74(1), 59-109.

\section{Arts Integration}

Catterall, J., Chapleau, R., \& Iwanaga, J. (1999). Involvement in the arts and human development: General involvement and intensive involvement in music and 
theater arts. Champions of change: The impact of the arts on learning, 1, $1-18$.

DeMoss, K., \& Morris, T. (2002). How arts integration supports student learning: Students shed light on the connections. Chicago, IL: Chicago Arts Partnerships in Education (CAPE).

Gullatt, D. (2008). Enhancing Student Learning through Arts Integration: Implications for the Profession. The High School Journal, 91(4), 12-25. Retrieved from http://www.jstor.org.proxy.lib.pdx.edu/stable/40364094

Hardiman, M., Rinne, L. and Yarmolinskaya, J. (2014), The Effects of Arts Integration on Long-Term Retention of Academic Content. Mind, Brain, and Education, 8, 144-148. doi:10.1111/mbe.12053

Hartle, L. (2015). ArtsIN: Arts Integration and Infusion Framework. Early Childhood Education Journal,43(4), 289.

Ingram, D., Riedel, E. (2003). What Does Arts Integration Do for Students?. Center for Applied Research and Educational Improvement. Retrieved from the University of Minnesota Digital Conservancy, http://hdl.handle.net/11299/144121.

Jewitt, C., Kress, G., Ogborn, J., \& Tsatsarelis, C. (2001). Exploring learning through visual, actional and linguistic communication: The multimodal environment of a science classroom. Educational Review, 53(1), 5-18.

Lin, C., Liu, Y., Huang, W., Lu, C., Teng, S., Ju, T., . . Hsieh, J. (2013). Sculpting the intrinsic modular organization of spontaneous brain activity by art. PLoS One, 8(6) doi:http://dx.doi.org.proxy.lib.pdx.edu/10.1371/journal.pone.0066761

Lynch, P. (2007). Making meaning many ways: An exploratory look at integrating the arts with classroom curriculum. Art Education, 60(4), 33-38.

Rabkin, N., \& Redmond, R. (2006). The arts make a difference. The Journal of Arts Management, Law, and Society, 36(1), 25-32 
Rinne, L., Gregory, E., Yarmolinskaya, J., \& Hardiman, M. (2011). Why arts integration improves long-term retention of content. Mind, Brain, and Education, 5(2), 89-96.

\section{Music in Education \& Brain Development}

Anvari S.H., Trainor L.J., Woodside J., Levy B.A. (2002). Relations among musical skills, phonological processing and early reading ability in preschool children. Journal of Experimental Child Psychology, 83, 111-130.

Bangerter, A., \& Heath, C. (2004). The Mozart effect: Tracking the evolution of a scientific legend. British Journal of Social Psychology, 43(4), 605-623.

Benz, S., Sellaro, R., Hommel, B., \& Colzato, L. S. (2016). Music makes the world go round: The impact of musical training on non-musical cognitive functions-A review. Frontiers in psychology, 6, 2023.

Cheek J.M., Smith L.R. (1999). Music training and mathematics achievement. Adolescence, 34, 759-761.

Giles, A. M., \& Frego, R. D. (2004). An inventory of music activities used by elementary classroom teachers: An exploratory study. Update: Applications of Research in Music Education, 22(2), 13-22.

Hetland L. (2000). Learning to make music enhances spatial reasoning. Journal of Aesthetic Education, 34 (3-4), 179-238.

Ho Y.-C., Cheung M.-C., Chan A.S. (2003). Music training improves verbal but not visual memory: Cross-sectional and longitudinal explorations in children. Neuropsychology, 17, 439-450.

Hurwitz I., Wolff P.H., Bortnick B.D., Kokas K. (1975). Nonmusical effects of the Kodály music curriculum in primary grade children. Journal of Learning Disabilities, 8, 167-174.

Hyde, K. L., Lerch, J., Norton, A., Forgeard, M., Winner, E., Evans, A. C., \& Schlaug, G. (2009). Musical Training Shapes Structural Brain 
Development. The Journal of Neuroscience : The Official Journal of the Society for Neuroscience, 29(10), 3019-3025. http://doi.org/10.1523/JNEUROSCI.5118-08.2009

Kraus, N., Hornickel, J., Strait, D. L., Slater, J., \& Thompson, E. (2014). Engagement in community music classes sparks neuroplasticity and language development in children from disadvantaged backgrounds. Frontiers in psychology, 5.

Kraus, N., Slater, J., Thompson, E. C., Hornickel, J., Strait, D. L., Nicol, T., \& White-Schwoch, T. (2014). Auditory learning through active engagement with sound: biological impact of community music lessons in at-risk children. Frontiers in neuroscience, 8.

Lamb S.J., Gregory A.H. (1993). The relationship between music and reading in beginning readers. Educational Psychology, 13, 19-27

López-González, M., \& Limb, C. J. (2012). Musical Creativity and the Brain. Cerebrum: The Dana Forum on Brain Science, 2.

Lynn R., Wilson R.G., Gault A. (1989). Simple musical tests as measures of Spearman's g. Personality and Individual Differences, 10, 25-28

Rogenmoser, L., Kernbach, J., Schlaug, G., \& Gaser, C. (2017). Keeping brains young with making music. Brain Structure and Function, 1-9.

Schellenberg, E. G. (2004). Music lessons enhance IQ. Psychological science, 15(8), 511-514.

Wan, C. Y., \& Schlaug, G. (2010). Music making as a tool for promoting brain plasticity across the life span. The Neuroscientist, 16(5), 566-577.

White-Schwoch, T., Carr, K. W., Anderson, S., Strait, D. L., \& Kraus, N. (2013). Older adults benefit from music training early in life: biological evidence for long-term training-driven plasticity. Journal of Neuroscience, 33(45), 17667-17674. 


\section{Current Events, Policy, Educational Stats, etc.}

Chu, Jane. (2017). Statement from National Endowment for the Arts Chairman Jane Chu on the FY 18 Budget. National Endowment for the Arts: News

Figueroa, A. (2013). 8 Things You Should Know About Corporations Like Pearson That Make Huge Profits From Standardized Tests. AlterNet: Education. Retrieved from:

https://www.alternet.org/education/corporations-profit-standardized-tests

National Assessment of Educational Progress. (2016). Nation's Report Card. 2016 Arts Assessment. Retrieved from: https://www.nationsreportcard.gov/arts_2016/\#/

Whitehorne, R. (2006). NCLB: Taking a toll on arts and music education. The Notebook. Retrieved from:

http://thenotebook.org/articles/2006/05/24/nclb-taking-a-toll-on-arts-and-music -education

\section{Homelessness}

Ayerst, S. L. (1999). Depression and stress in street youth. Adolescence, 34(135), 567.

Casey, B. J., Jones, R. M., \& Hare, T. A. (2008). The Adolescent Brain. Annals of the New York Academy of Sciences, 1124, 111-126. http://doi.org/10.1196/annals.1440.010

Edidin, J. P., Ganim, Z., Hunter, S. J., \& Karnik, N. S. (2012). The mental and physical health of homeless youth: a literature review. Child Psychiatry \& Human Development, 43(3), 354-375.

Harris, L. T., Fiske, S. T., (2006). Dehumanizing the lowest of low: Neuroimaging responses to extreme out-groups. Psychological Science, 17(10), 847-853

Smedley, B.D., Stith, A.Y., Colburn, L., et al. (2001). Inequality in Teaching and Schooling: How Opportunity Is Rationed to Students of Color in America. Institute of Medicine (US). 
